\title{
Managing Water and Wetlands Based on the Tayal's Interpretation of Utux and Gaga
}

\author{
Kuoyung Silan Song (宋國用) ${ }^{1} \cdot$ Ben LePage $^{1,2}$ (1) $\cdot$ Wei-Ta Fang ${ }^{1}$
}

Received: 10 December 2020 / Accepted: 8 June 2021 / Published online: 2 October 2021

(C) The Author(s) 2021

\begin{abstract}
Humans first appeared on the planet about 3.5 million years ago and like most biota, they settled near wetlands because of the availability of food and water. The ancestors of our species understood and knew that water, wetlands, and healthy landscapes were essential for life. In Taiwan, the indigenous people have a long history being a part of and managing the natural resources, including wetlands in their respective habitats. Water and wetlands still play a substantial and significant role in the manner that the Tayal, an indigenous group of people in Taiwan use, preserve, care, protect, respect, and share the habitats and natural resources within which they live. The evolution of Taiwan's tribal cultures, and probably most cultures on the planet are closely entwined with the resources present in each tribe's habitat, especially water and wetlands. DNA results indicate 2 lineages of people migrated to Taiwan between 11,000 and 26,000 years ago and gave rise to 9 ethnic groups (Tajima et al. 2003). Today 16 indigenous cultures/tribes are recognized with each occupying different regions of Taiwan's diverse landscape. Each tribe has its own language and culture and occupies its own geographic region, which contributes to Taiwan's rich cultural history and diversity. The Tayal tribe is one of the larger tribes with about 88,000 people and the Smangus people are a subset of the Tayal tribe with a culture that is at least 6,000 years old. Culturally, the Tayal people consider themselves to be an element of the environment and their culture is defined by their relationship and interactions with the environment, including all of the other biotic, abiotic elements present in their habitats. In this paper we provide an overview of Tayal culture and philosophy, which determines how the Tayal people manage and protect their natural resources, especially water and wetlands following the tenets of Utux and Gaga that comprise the entirety of their core cultural values. The cultural and language variations, nuances, environmental interpretations, and management techniques are specific to tribal groups and differences in geographic location and environmental settings.
\end{abstract}

Keywords Atayal · Culture · Communication · Environmental · Gaga · Gogan · Paradigm · Rituals · Sbalay · Smangus · Spirituality $\cdot$ Stakeholder engagement $\cdot$ Sustainability $\cdot$ Tayal $\cdot$ Utux $\cdot$ Water $\cdot$ Wetlands

\section{Introduction}

Little is known about ancestral Taiwanese cultures such as that of the Tayal people outside of Taiwan. The Tayal culture is based on Utux and Gaga. Utux (=God) is a system of

Ben LePage

benlepage2@gmail.com

1 Graduate Institute of Environmental Education, National Taiwan Normal University, No. 88, Section 4, Ting-Chou Road, Taipei 11677, Taiwan, Republic of China

2 Academy of Natural Sciences, 1900 Benjamin Franklin Parkway, Philadelphia, PA 19103, USA animistic beliefs, which is the essence of their spiritual and cultural values within which their moral rules, habits, and beliefs, called Gaga are embodied (Chen et al. 2018; Fang et al. 2016; Tang and Tang 2010). Although the cultural norms, values, and practices of the approximately 88,000 people that are distributed over approximately 209 Tayal tribes in Taiwan are similar to one another, the Tayal culture is not entirely homogenous. Wetlands are important natural resources that each tribe uses and manages differently based on their value or need of these resources and cultural norms. The knowledge and practices of one Tayal tribe cannot be equated with the collective knowledge and culture of the Tayal people or Taiwan's 15 other indigenous cultures (Fig. 1a). The activities and practices of each tribe are shaped by the environment within which they live and temporally, 
because they've been working with and generating data on wetlands for thousands of years, largely to keep their people and culture alive. In fact, the Tayal people probably know more about certain aspects of wetlands than do wetland scientists. Despite the incredibly valuable data that wetland scientists have generated over the last several hundreds of years, indigenous knowledge and management approaches are different and have a much longer history and are equally valuable.

An important difference between most indigenous tribes of the world, including the Tayal and western science is the manner in which the data are collected, interpreted, and communicated. The Tayal collect data through observations and validate their observations by applying what they've seen or learned in their daily activities. Useful data are then incorporated into their knowledge base and management systems are built around this knowledge base and then transmitted to members of the tribe and subsequent generations orally. The Tayal have no writing system in their culture to document their tribal or collective knowledge. Therefore, language is the medium used to transfer information among and between individuals, which makes language and linguistics (i.e., the words used and how they are used) significant cultural components.

To better understand the nexus between language/linguistic meanings, culture, and environmental practices we interviewed Smangus and other tribal elders concentrating on interpreting and understanding the meaning(s) of their words, associated with their cultural practices that are associated with water and wetlands. We also observed tribal member behavior towards wetlands and other natural resources in a contemporary context. The Smangus people are a subset of the Tayal with a 6,000-year-old culture and their use of the natural resources in their respective habitats is systematic and rational because they recognize and understand the carrying capacity and ability of the land that they live on to replace the resources that they consume. The thesis of this paper and KSS' dissertation research was aimed at assessing the Tayal tribe's individual and/or collective perceptions of Utux and Gaga and relationship(s) between tribal culture and the wetlands and natural resources in their habitats. Utux is a system of animistic beliefs, which is the essence of their spiritual and cultural values within which their moral rules, habits, and beliefs, called Gaga are embodied (Chen et al. 2018; Fang et al. 2016; Tang and Tang 2010). The Tayal people's environmental literacy is shaped by Gaga and Utux. Therefore, our first task was to validate the tribal member's views on Utux and Gaga, linguistic meanings and concepts, their cultural relationship with the environment, resource use and management, and sustainability by interviewing tribal elders. Second, we observed and interacted with tribal members in their day-to-day activities to verify and/or clarify the linguistic meanings and concepts of the Tayal knowledge base that were obtained through interviews with the elders.
Most Tayal tribal members understand how ecosystems function within their respective habitats without a formal background or training in science. For the Tayal people the physical and cultural components of the people and their environment are one in the same. We presume that this belief is consistent in all of Taiwan's indigenous cultures; however, understanding and discussing the relationships and nuances of each indigenous culture in Taiwan and others throughout the world for that matter, are well outside of the scope of this paper and we concentrated only on the Tayal people and their culture. We also identified a number of elements in the Tayal culture that are related to their knowledge base and resource management systems that could be of value to western scientists, but the semantic issues associated with Traditional Ecological Knowledge (TEK) and Traditional Ecological Management (TEM) and breadth of this topic precludes us from discussing TEK and TEM in further detail in this paper. Nevertheless, we should not forget that the Tayal wetland and resource knowledge base and management systems are specific to the needs of the people and in principle differ from those developed and used by western scientists, and when used together they may contribute to solving some of the global environmental and wetland issues we currently face. As such a more detailed analysis of Tayal TEM and TEK is warranted in the future.

\section{Materials and Methods}

The Tayal people occupy 9 watersheds in Taiwan and today there are about 209 Tayal tribal groups that live in Nantou County, Taichung City, Miaoli County, Hsinchu County, Taoyuan City, New Taipei City, and Yilan County (Fig. 1b). Fifty-eight Tayal (58) tribes comprised of about 15,000 people live in the ecologically complex Gogan River (Dahan River in Chinese) watershed in Fuxing District and Taoyuan City. A sub-set of these tribes was selected for this study because the language dialects were similar to one another. This approach allowed us to focus on the linguistic meanings of words and concepts associated with the wetland resources related to environmental management and sustainability practices in the tribe's respective habitats. According to the elders and their oral history, the environmental impacts in the Gogan River watershed have been minimal and they believe this has contributed to the harmonious coexistence of the Tayal and their culture with the natural environment in this watershed for thousands of years. The responses used in our analysis spanned a decade, providing an important temporal aspect to the responses that might show whether aspects of the culture were static or in dynamic equilibrium (=adapting) to environmental and social change.

Interviews and observations were conducted by KSS with tribal elders and seniors mostly over 60 years of age that had 


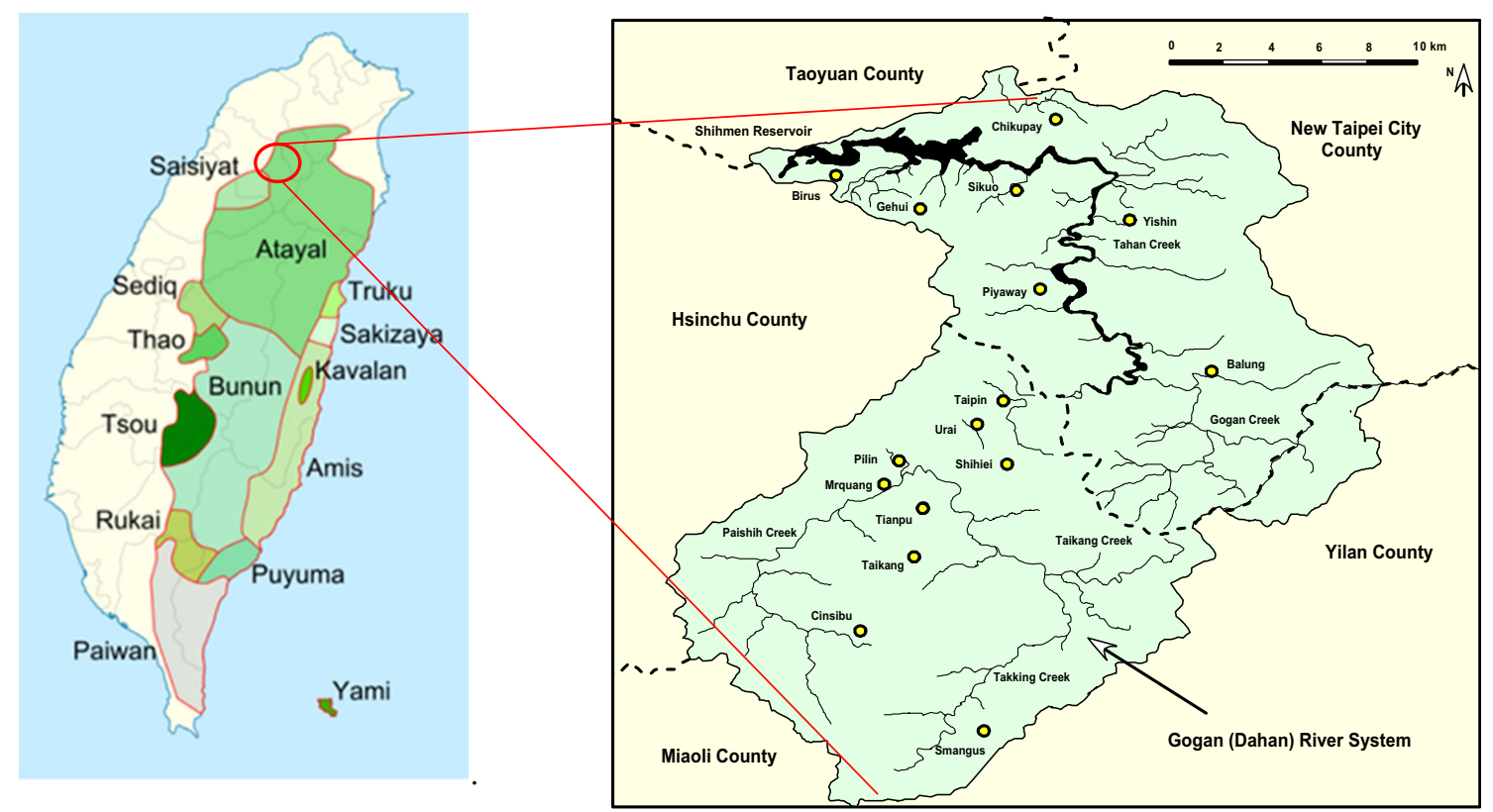

Fig. 1 a Approximate territories of the 16 indigenous tribes in Taiwan. Source: <https://en.wikiquote.org/wiki/File:General distribution of indigenous people in Taiwan.svg $>$. b Approximate locations of the indigenous tribal groups of Tayal people in Taiwan that were surveyed in this study. Source: Redrawn and modified from $<$ https://nccur.lib.nccu. edu.tw/bitstream/140.119/50440/1/10.\%E5\%AE\%98\%E5\%A4\%A7\% E5\% 81\%89.pdf> knowledge of Tayal tribal rituals and how the rituals are to be performed between 2009 and the 2020 (Table 1). At least one person from each tribe was selected to be interviewed. Sixteen (16) elders were interviewed from the following areas (=Li): 1 person in San-min Li; 2 people in Tse-ren Li; 1 person in Xiayun Li; 1 person in Yi-sheng Li; 2 people in Lo-fu Li; Changxing Li 2 people; 2 people in Qwe-hwei Li; 2 people in Kao-yi $\mathrm{Li}$; 1 person in San-kwang Li, and 2 people in Hwa-ling Li. These data were used to better understand the Tayal's thousand-year-old cosmology (= belief system) and their relationship with the environment, specifically wetlands and their environmental stewardship and sustainability practices. The interview questions were aimed at assessing the tribe's individual and/or collective perceptions of Utux and the relationship(s) between Tayal tribal culture and the tribe's wetlands and natural resources. We use Cowardin's (1979) definition of wetlands, which includes rivers, streams, standing water, groundwater and therefore our use of water, rivers, and wetlands in this paper are used interchangeably. A list of these questions is provided in Appendix 1. Responses are provided in Appendix 2 and excerpts that best illustrate the points that we are making in this paper are woven throughout the text to illustrate the importance of a belief. The concept of tradition can often be over-shadowed by opinion, clouding people's interpretation of concepts, linguistic origin, and meaning, thereby introducing controversy in the meaning of the words, sentences, and/or concepts because its difficult to distinguish whether oral or undocumented vocabularies are original or have been changed because of spatial, temporal, and contextual meanings amongst tribal members. This is a limitation of this type of research, but we believe linguistics is a good way to identify the traditions (i.e., this is what our ancestors did) and the culture of the people. A semistructured interview approach was used because it allowed the same open-ended questions to be asked to a large number of people and provided KSS with the flexibility to follow a line of thought that an elder considered important. Moreover, interviews tend to be more accurate than surveys (https:// thesislink.aut.ac.nz/?p=6198).

The observations were concentrated on tribal ecological and agriculture practices, ceremonies, rituals, and the manner in which the people protected their aquatic resources. The locations, number of Tayal people we interacted with, and dates of the observations are as follows. Some of the tribe also have Han Chinese people as part of the tribe, so we identified the Tayal people that we interacted with. In 2016 we observed and studied the ecological and agricultural practices of 5 tribes in Yufeng and Xiuluan Villages, Jianshi Township, Hsinchu County, with about 50 people. In November 2018 we visited the Smangus tribe to observe the current status and effectiveness and practice of the tribal ecological management systems and hear words of goodwill of the tribal elders' (ca. 30 people people). In July 2018 we concentrated on tribal member beliefs and practical reality of the rituals of the Tianko tribe, Tai- 
an Township, Miaoli County and about 120 people participated in smyus, an ancestral sacrifice ceremony. In August 2017 we participated in in 9 Tayal Townships that held smyus ceremonies in Ren-ai Township we interacted with about 1,500 people to better understand how the tribe performs a ritual, holds celebrations, and land and water resources management and utilization practices. In October 2017 we participated in Sbalay, a reconciliation ceremony for a hunting ground dispute between the tribes in Datong Township, Yilan County and Fuxing District. About 500 people participated. On August 2019, we participated in smyus activities in the Fuxing District Office and in Sanqwang Li in October 2019. Both events attracted about 5,000 people, including tourists. These observations allowed us to assess the Tayal people's belief system, truth, reality, interpretation of the environment, and environmental literacy as they relate to Utux and Gaga. Of the rituals, we concentrated how the Sbalay ritual was performed and its use to resolve disputes among and between tribes. These data were then used to supplement the elder's responses and illustrate the Tayal rituals that follow Utux and serve as important benchmarks that demonstrate the environmental ethics practiced by the tribes and its members. The observations also provided a means to compare and contrast Tayal practices, rituals, and language of the people within the tribal groups that we assessed. The interview and observation data demonstrated how information and practices were being interpreted (personally or collectively) and passed to other members of the tribe.

\section{Results and Discussion}

The Tayal people's environmental literacy is shaped by Gaga and Utux. "Gaga na cinnunan na cinbwanan" is the environmental ethics of Utux and relationship between the sky, earth, and people. The Tayal believe that the sky is a being and Utux creates and weaves the ethical rules that unite the people and their habitats into one. It provides the people with the tenets needed to assimilate the physical and spiritual relationships between humans and their environment. Gaga can be classified into four levels of belief-knowledge-normative and institutional meanings that constitute the continuum of Tayal environmental literacy (Fang et al. 2016: Berg 2013; Tang and Tang 2010). They include: beliefs; knowledge; regulation (taboos, prohibition); and social convention. While each category may appear to be discrete, the overlap between categories can be substantial. For example, based on context, social convention could also be considered a belief, a taboo, or knowledge.

Variations in Tayal tribal culture and their relationships with the environment are unique to each tribe. The Tayal understand that their people reside in different habitats of a larger watershed and use the resources differently, but collectively they recognize that the Tayal people and their respective habitats are part of the larger Tayal culture. The ecological mosaic of habitats not only contributes to the abiotic character and variability of the region, it also plays a large role in shaping cultural diversity within and between tribes. We were interested in the consistency that Utux and Gaga were/are being interpreted and practiced within and between tribal groups, realizing that subtle differences would be expected in the Tayal cultural continuum. As is the case with any culture on the planet, the Tayal culture is spatially and temporally complex that evolves in the same way living organisms do when faced with change. That is, adapt, move, or go extinct. We also concentrated on the influence that water and wetlands in the respective habits of the Tayal tribes had/ have shaping the tribe's views and beliefs in Utux and Gaga.

\section{Beliefs}

The Tayal believe Utux has true gods, good spirits, bad spirits, evil spirits, wandering souls (behuy), and ghosts (Table 1). It is wise to keep good spirits in one's Gaga throughout life. After death a person goes to "intuxan", the ancestral spirit world. Both evil and bad spirits are called ghosts. People who are evil in life become evil or bad spirits in death and continue to harm the human world. God (=Utux) is called a woven spirit, and good spirits are those that will have a good destiny, and vice versa. Utux is found in mountains and rivers, rock, plants and animals (Respondent, 090706). The spirits and ghosts of Utux all possess spiritual power and functions. The spirits in the sky form after the death of an individual and the people consider them to be the tribe's Utux bnkis (ancestral spirits), which demonstrates the Tayal's belief in immortality (Berg 2013; Cajete 1994). The heavenly spirits are beings that have their own life form and include biotic and abiotic elements of the environment, which includes water and wetlands (Cajete 1994). The spiritual views are constructed by the people of the Tayal tribe's view of Utux and the importance that they would place on resources such as wetlands. The people of the tribe also recognize that these spirits have powers, which deeply influences their behavior (Chen et al. 2018). Spiritually, this means the people are simply an element of the natural resources in their respective habitats. The existence of spirits in the sky with supernatural powers appropriately describes the Tayal's people's multidimensional view of the spatial and temporal space in their culture.

The relationship between kayal (sky), hiyal (earth), and Tayal is kayal rules the creation of all things. Hiyal is the body of the spirit of kayal and the Tayal people live in that celestial body. An elder's explanation is presented as follows. Kayal, in addition to meaning sky also means speaking. When talking, the use of kayal ta ke implies the conversation is related to 
Table 1 A subset of tribal members, consisting of tribal elders who provided data for our analysis

\begin{tabular}{llllll}
\hline Code & Tribe & M/ & Age & Years of Work & Job Title \\
& & F & & & \\
\hline 0900706 & Elder (Birus) & M & 90 & Retired & Priest/Cultural Worker \\
090612 & Elder (Keikoray=kekorai) & M & 79 & Retired & Priest/Cultural Worker \\
090612 & Elder (Gehui=Qehui) & M & 85 & Retired & Farmer/Hunter Gatherer \\
150,720 & Elder (Keikoray=kekorai) & M & 66 & 20 & Farmer/Cultural Worker \\
160,314 & Elder (Shihiei=Shihlei) & M & 79 & 60 & Farmer/Hunter Gatherer \\
160,315 & Elder Mrqwang) & M & 77 & 50 & Farmer/Hunter Gatherer \\
160,315 & Elder Mrqwang) & M & 68 & 20 & Priest \\
160,316 & Elder (Tian-pu) & M & 80 & 70 & Farmer/Hunter Gatherer \\
160,317 & Elder (Cinsibu) & M & 77 & 30 & Priest/Cultural Worker \\
160,317 & Elder (Cinsibu) & M & 73 & 50 & Farmer/Hunter Gatherer \\
170,621 & Resident (Tian-pu) & F & 45 & 30 & Christian Pastor/Cultural Worker \\
170,630 & Resident (Cinsibu) & F & 32 & 20 & Christian Pastor/ Tribe Guide \\
170,705 & Resident (Pilin) & F & 63 & 50 & Cultural Worker/ Christian Pastor \\
170,705 & Resident (Urai) & M & 72 & 50 & Farmer/Hunter Gatherer \\
170,630 & Resident (Balung) & M & 70 & 50 & Farmer/Hunter Gatherer \\
170,703 & Elder (Keikorai=keikoray) & M & 68 & 30 & Farmer/Hunter Gatherer \\
171,115 & Elder (Smangus) & M & 68 & 30 & Farmer/Hunter Gatherer \\
\hline
\end{tabular}

*Code: The first two digits represent the year, and the last four digits, month and day of the interview. The interview spans different years and tribes, which contributes to detecting new views and differences in the elder's opinions/beliefs in different years and tribes for discussion heaven or spiritual powers and therefore, lying or deception are not allowed because Utux is watching. Utux dominates everything, and everything is changed by heaven, and we cannot change heaven. Hiyal means land and/or heavenly body, including its natural resources. In the Tayal language, hiyal is not only the earth, but also the heavenly body. Lhiyal means a land that has grown many resources that are gathered and lhuiy, means seeds and a land that grows many resources. Seeds will continue to grow naturally, but humans, animals, and plants are trained by the celestial bodies and all must be treated with gratitude because it's the people's duty to protect them. As pointed out by an elder "Heaven" is the power that governs all people or all things (Respondent, $150,720)$. Although this narrative may seem disconnected from our thesis, it demonstrates that every word in the Tayal language has meaning, depending on the context or situation and these are the nuances that comprise the linguistics that are an important part of the Tayal culture. This is an important aspect of the Tayal culture because if the generation (s) receiving the knowledge being passed to them have lost the ability to interpret what is being said or intended, then the knowledge or concept is lost. Given that their culture is closely tied to the environment and its natural resources, the approximately 6,000-year history of the Tayal's knowledge of wetlands and other natural resources in Tayal habitats are at risk of being lost too.
In tribal life the activities of the Tayal people have an awareness and ability to shuttle, communicate, reconcile, and balance personal experience with the spirits in their respective tribal cultures. This requires experience with learning and performing rituals and spiritual communication skills. The people all fear and/or revere the spirits. Spiritual power is divided into (1) the spiritual power of other-than humans (non-humans) and (2) human rituals. Under Utux, both humans and non-humans are treated equally and wetlands/ water are considered non-human elements. Utux creates balance in a highly complex, but interconnected (Tminun) system that binds the social, cultural, and ecological aspects of a people and their environment into one. Collectively, the interactions between humans and other-than humans comprise the tribe's environmental awareness and their relationship between one another and interactive mode to maintain tribal, cultural, and environmental harmony. The tribal elders all agreed that when people do bad things and do not protect or practice their Gaga, their lives could be harmed by a supernatural power at any time. Given that a person is a member of a tribe, their perceptions and behaviors can also be extended to the entire tribal group, putting the overall safety and wellbeing of the group at risk (Tinker 1996; Cajete 1994). Gaga is the Tayal people's way of knowing, doing, and adapting, to changing environmental and/or social conditions in space and in time. Gaga however, can be ambiguous because it has 
many complex characteristics that change with context, tribal groups, people within the tribal groups, space, and time. Simply explained, their practice and belief in Utux and Gaga is their reality and culture, which implicitly requires them to protect their natural resources and practice natural resource sustainability (Chen et al. 2018; Fang et al. 2016). The people's innate desire to be responsible environmental stewards is not an accident. This is a crucial element of their culture that is passed from one generation to the next. The Tayal's metaphysical rituals further express that their belief in Utux is real.

The llyung (river) is an important place for Tayal cultural heritage. According the elders, the Tayal people did not use water for irrigation, bring it into their homes, or even build houses near the water. In the past, the introduction of water into the house was considered a taboo because of the threat of hmor (flooding). Therefore, the people would rather go to the river to carry water to their homes. But with changes in farming culture and economic development, living near water is no longer a taboo. However, the Tayal recognize floods bring disasters that must be avoided or guarded against before having their homes blessed by the ancestral spirits. This change in their Gaga illustrates their ability to understand how ecosystems function and ability to adapt to changes in environmental conditions and social conventions, which demonstrates the temporal adaptability/flexibility of their culture. That is, their knowledge base, management strategies, and relationship with the environment are not static. Fishing methods are another example of adaptation and a good demonstration of environmental stewardship and sustainability. In the past the fishermen that used nets to fish were ridiculed because they were not mliquy balay (real Tayal men). But over time and in addition to the social pressure of not being mliquy balay, the fishermen realized that netting was not a sustainable practice and contributed to the adoption of the fishbone method that they now use.

As is the case with most people, common beliefs facilitate strong forms of unification. An elder iterated, If we have forests, land, and water, we can survive. When we heard that the government was going to set up a large dam in the Mrqwang Valley, we gathered young people who were studying outside to return to the tribe to discuss how to solve it. The tribe crowd was so angry that they wanted to block the road and even threatened to kill one by one. The current government decree does not allow us to do this. We have inherited this issue from our ancestors in Gaga, so we can protect our watershed. The elderly still think that we should discuss it rationally. If the dam is built, where are we going? How is our culture maintained? Discuss what to do with the ancestor's land. The river is the source of our life, and the land is our mothers and ancestors. In the past, we were forced to speak Mandarin, but now we are forced to leave. How can we continue our lives and develop our culture? And how to unite people from other tribes. This is where we must build a consensus to unite and reflect our aspirations to the government. The tribal boundaries are very good. Gaga is bounded by the middle line of the river. The Mrqwang Group and the Mknazi Group are bounded by the flagship rock, which is also a planned site for large dams planned by the Taiwan Government (Respondent, 160,315)". This statement effectively sums up the relationship that the Tayal people face with respect to environmental issues, management strategies, and progress overarched by global change.

In Tayal culture, the ancestral spirits are the protectors of the environment. The responsibility of the ancestral spirits is to transfer the tribe's environmental resources such as their habitat and the tribe's culture to the next generation. The contemporary practice of Sbalay demonstrates a Tayal reconciliation ritual that is performed between tribes and stakeholders regardless of the complexity of the issue. In this case, the tribes successfully protected the land that was left by their ancestors and perhaps had an opportunity to re-evaluate the value of their relationship with nature. Because the Tayal were aware of the environmental hazards associated with hydroelectric dams, they were particularly sensitive that the middle and lower reaches of their watershed were subject to irreversible environmental damage and their culture when a dam was proposed to be built in their watershed. The elders firmly said that money cannot lure the tribal people to sell the natural resources left to them by their ancestors. The elders cared about implementing sustainable development practices so that the environmental resources, habitats, and culture of the tribe(s) are preserved. Despite the opportunity to sell the land for millions of dollars, the elders refused because the ecosystems in the watershed demonstrated Tayal lifestyle, their connection to ancestral lands, and the culture of their people, which was of far greater value than the money. An elder summed it up appropriately by stating "Your money is very good, but your money cannot recover and protect our culture. However, the buyer did not give up and returned with more than 50 million yuan in cash." The elder again told him: "Your money is good, but your money cannot cultivate and nurture our millet and sweet potatoes, nor can it continue the lives of our children and grandchildren (Respondent, 171,115).

\section{Knowledge}

The Tayal's understanding of ecological concepts is holistic and the development of their knowledge of ecosystems follows procedures and processes that are substantially different than those used by western scientists. It doesn't mean that their data are incorrect compared to data generated using western scientific methodology, it just means that the Tayal's approach to gathering and processing data are different from that of western scientists and serves a different purpose. The Tayal habitat consists of the space where the people interact with their environment in accordance with their cultural norms, and 
values. Over time their understanding of the biology and resources in their habitats increased, thereby adding to the tribe's respective knowledge of ecosystems and management systems. Aspects of how ecosystems function and the relevant ecological benefits that sustained their people became incorporated into their culture and language. The ability to effectively communicate this information to future generations meant that their people got to live. The development of tribal TEK and TEM systems provides good insight into their relationship between the people, culture, ideas, and etymology. These elements are further sharpened by the Tayal social, communication, and cultural networks that contributed to their survival.

The concept of a connection between the people and environment is similar to that discussed in Berkes (2012), who recognized that the indigenous people of the world adapted to the environment through beliefs, rituals, taboos, and social convention. This is obvious given that the Tayal people have been interacting and understanding how ecosystems such as wetlands in their habitats functioned for their people to live for about 6,000 years. Strictly speaking, the concept of environmental literacy of the Tayal people is based on their language, tradition, and oral history, not the methodology used to manage the natural resources that they needed to stay alive or their level of education. The Tayal have no written records that define or explain their body of knowledge of the ecosystems in their habitats and the management systems that they developed over generations. Had they needed to follow methodologies more aligned to western science in order to survive, the scientific methodologies of both groups would probably be much more closely aligned with one another. The elders indicated that their relationship with the environment is based on the Tayal people's inherent understanding of what is right or wrong, which equates to the concept of natural law and adaptability of the people to an environment with constantly changing biotic and abiotic conditions.

The tribal elders pointed out that the habitats in the Gogan watershed inspired their people to maintain a rich natural peaceful life following the core principles of Utux. They further indicated that these types of ecological settings allow the people to coexist harmoniously with their natural environment because the people in the Tayal culture are an important component of the environment. As curators of the Tayal's collective culture and knowledge, the elders are therefore responsible for collecting, retaining, processing, and interpreting data on all aspects of Utux, rituals and how they are to be performed and why, ceremonies, ethics, and morals without a writing system. They need to process these data in accordance with the needs of the tribe at that time and facilitate the analysis and understanding of spiritual entities, meanings, and effects on the people that build the foundation of their culture and environmental philosophy. They observe, interpret, and advise tribal members on how these metaphysical concepts are implemented in the practice of environmental ethics, sustainability, and behaviors that reflect their reverence and respect for nature.

The integration of modern scientific approaches that are about 1,500 years old with those of the indigenous Taiwanese cultures that could have up to 26,000-year histories, into a unified system that the indigenous and western scientists, as well as humanity can use and understand is probably the biggest challenge both groups face. The data generated by both groups are equally valid, but provide answers to different questions and cultural values. Berg et al. (2017) for example noted traditional restoration targets and forest management systems in Tayal territory impeded cooperation between the indigenous and non-indigenous stakeholders because the history of the local people was discounted. Zebardast et al. (2020) reported several resource management projects in Iranian wetlands failed because the projects lacked a collective decision-making process that included the indigenous community. The Tayal forest classification system bears no resemblance to any modern classification system used in plant taxonomy because it is based on Tayal culture, within which the understanding and use of the forests, results in a biophysical and cultural-historical classification system that is of little use to ecologists (Berg et al. 2017). Nevertheless, the value and usefulness of Tayal knowledge should not be diminished because the Tayal and other indigenous cultures have subsisted on these resources for generations. To be blunt, they are clearly doing something right.

Sharing is a part of Tayal culture and financial economy is not an important consideration. Tribal boundaries do not infringe on one another, prevents the excessive use of the natural resources, and builds their value for a balanced relationship between humans and nature. The Tayal distribution and use of natural resources and their rights associated with these resources is sound, but doesn't necessarily always occur as planned. As outlined in Hardin's (1968) tragedy of commons theory, regardless of the natural resources, elements such as the physical boundaries, location, geology, soil, and hydrology contribute to wetland presence/absence. A change in any one of these characteristics could change or eliminate a wetland. For example, if a typhoon passes, the rivers and wetlands may then restore themselves naturally or disappear. In situations where rivers are impacted and the fish population disappears the Tayal will often capture fish fry from downstream or upstream sources and then release them to the impacted river section that has been restored and rehabilitated (Fang et al. 2016). Fish fry are treated as carefully as humans. This kind of shared environmental management practice is valuable information that has been passed through generations of Tayal people. This is the Tayal "cinbwanan" (environment), which includes the mutual connection between human, spirit, and nature. 


\section{Social Conventions and Regulations}

Regulations may purposefully be built into Tayal procedures, processes, and social conventions. How the Tayal carry out certain activities are governed by their culture, but it must be remembered that everyone in the tribe is watching how well or poorly the activity is performed. Therefore, the distinction between following regulations and social convention are blurred and often hard to separate. For example, the Tayal people's mlahang (care) of water will not allow them to disturb streams or rivers on purpose. Their Gaga reinforces practices to maintain the natural bed of a river/wetland, which can be difficult depending on the task. The elders firmly believe that the Tayal can't live without Utux and use the concept of "nyux mita Utux" (Utux is watching), which is laden with metaphors that use spiritual power as the persuader. For the Tayal people, it produces "saniq" (taboo) that helps modify their behavior and over time, these beliefs and modified behaviors have become part of their culture. As pointed out previously, these spiritual beliefs remind the people that Gaga, tribal beliefs, and practices need to be followed because everyone inside and outside of the tribe, including Utux is watching. Tribal members also understand that it's in their best interests and those of the tribe to follow the rules. For example, drowning is forbidden. Fishermen are required to perform rituals before they enter the water so that they can fish safely. Not only is the ritual culturally important, it provides situational awareness and forces the person to think carefully about what they are about to do. Eating by the side the stream also allows a person to share and experience the spirit of the stream. The ability to stop and think, provides time for people to assess their activities, reflect, and show respect for the stream and nature.

Ancient Tayal rituals are still being practiced today and support the conclusion that Sbalay is an effective and important ritual that could be adopted in a modern world to help solve controversies between Tayal and non-Tayal stakeholders today. In 2016, Taiwanese President Tsai Ing-wen promoted the word Sbalay to the national level of ethnic "reconciliation", commending that Sbalay still has meaning among the Tayal tribes today and needs to become known nationwide (https://english.cw.com.tw/article/article.action? id=2495; https://english.president.gov.tw/NEWS/4950). Sbalay is an important reconciliation ritual that brings balance between (1) humans and humans, (2) tribes and tribes, (3) and ethnic groups and countries, and (4) humans and other than humans. A good example of this social convention and ritual was the plan to build the Kaotai Reservoir in the Mrqwang and Mknazi tribe's watershed. The Mrqwang and Mknazi tribes had little contact in the past and the proposal to build a reservoir in their watershed threatened their habitats and cultures. Sbalay provided a good opportunity to resolve their differences, unite, and cooperate to achieve a common goal. The tribes abandoned their individual interests and united to oppose the proposal to build a high platform dam on Mrqwang Creek. The elders also indicated that these tribes have never held a formal reconciliation ceremony in the last century and the proposed construction of this dam and its associated environmental impacts brought the tribes together. On a high platform the elders of both tribal groups used bamboo cups to hold millet wine, dipped their fingers in the wine to taste, and swore to the heavenly spirit to reconcile and promise/commitment to express their respective ethnic group's participation in opposing the construction of Kaotai Reservoir. These actions protected their homes and by default, their habitat and culture. Later, the Tayal people successfully established their own lobby group using their beliefs and the ability of the ancestral spirits to protect their environment, which united the under-represented and smaller tribal groups into a single voice. In addition to eliminating past grievances between these tribes, Sbalay allowed them to form a unified front that opposed the construction of two other large dams and reservoirs in their territory.

In 2019, we participated in an Ancestral Spirit Ritual, called smyus in the downstream and upstream regions of Fuxing District. Smyus is the ritual of food delivery to the ancestral spirits and an important ritual in the Tayal household that is usually held before dawn. While our data support the concept that Utux is real and the Tayal people's believe in Utux, it became apparent that modern society, including the Tayal have lost the ability to interact with the environment in the ways that our ancestors did in the past. Soga and Gaston (2016) call this the extinction of experience, which is the loss of interaction with nature that diminishes human health and well-being, positive emotions, attitudes, and behavior towards the environment. For the Tayal people, this not only means the loss or minimized interactions between the people and the environment, but a loss of their culture and identity. In this case it's important to remember that our ancestors and those of the Tayal survived because they adapted to past global/environmental issues because they couldn't change them. The alternatives were dire; move, adapt, or go extinct. While there is little that we can do to reverse or reset the environmental conditions that our ancestors experienced thousands of years ago, we can learn from our ancestors and adapt to changed/changing conditions.

Our study shows that the Tayal can be divided into tribes and ethnic groups with different levels of defense rights. According to an elder: Our Gaga is very good, that is, our life culture, and my father did not talk about the specific content. But the sharing of pork is a good example, regardless of whether young or old men and women share equally, this is our Gaga. Tribal boundaries are based on the ridgeline of a ravine or mountain, and streams are based on ethnic groups. Adherence to the local of Gaga, whether it is a tribe, hunting area or the use of water, you must first obtain the consent of 
the tribe that occupies or has responsibility for the resource and share a pig (Respondent, 170,630). In the context of Gaga, the norm of first-come first-occupation (= first-served) is followed. This requires people/tribes entering an area to obtain consent from the tribe that first found and/or possess the land or resource to use these resources or occupy the land. This practice contributes to recognizing of the carrying capacity of the land and sustainable use of its natural resources (Chen et al. (2018). The concept of first-come first-served plays heavily into how the Tayal view their habitat and share its resources.

The Tayal are called llyung Gogan (Dahan creek in Chinese) and from the downstream to upstream areas each tribe follows their Gaga, guarding their respective water systems in a peaceful and orderly fashion. The first uru (water ravine) is the main water resource for households in the mountain areas and the first people there have the right of first to use. Stated previously, latecomers must get permission from the first occupants before they can use the water and/ other resources. Furthermore, the first occupants have the right to defend their land and resources against people outside of their tribe, but sharing is a Tayal trait and rarely do the Tayal revert to aggressive measures. Second, the gong (creek) and llyung are used for fish collection and cultural activities. The Tayal rights are divided by the section of the stream passing through the tribal area with each section bounded by prominent physical features such as mountains and ravines or the middle of the river and define the tribal boundaries. The ownership and defense rights are conferred under each tribe's Gaga. The scope of these rights includes water, land, and attached possessions. This is possibly the closest set of guidelines to a modern regulatory framework that we've seen in the Tayal culture. Dispute of rights between and within tribes are all resolved through Sbalay, where the right to defend/protect their resources is accepted and understood by the stakeholders following their Gaga. Once the issue has been resolved the party that made the mistake provides pigs to be shared between tribes. Pigs are the totem of spiritual sharing and represent the offerings recognized by all tribes and their sincerity. The importance of this ritual is the sincerity of the confessing party and indicates that the dispute is over.

Some wetlands are given special status in Tayal culture. For example, the wetlands and associated Taiwania cryptomeroides (cypress) forests of the high-altitude areas have been fiercely protected for thousands of years. These forests in the Smangus tribal areas are called yaya parung (Berg 2013; Berg et al. 2017), which gives them equality with humans and a respected status that shapes the people's cultural identity. As it turns out habitats in a Tayal watershed are segregated vertically. In the llyung Gogan watershed the Mknazi and Malipa people live in the lower reaches, the Malipa occupy the middle reaches, and the Mrqwang tribe occupies the upper reaches of the basin. Baishi and Taikang
Creeks, both of which discharge into llyung Gogan are occupied by the Mknazi tribe and Takking Creek by the Smangus tribe. The habitats and wetland resources that span thousands of vertical feet of elevation are vastly different ecologically, and provide the tribes with their unique cultural identity. The ecological resources are the main body of rights between the tribes that occupy this vertical space and associated habitats. The llyung Gogan and its tributaries is considered to be the mother river that nurtured the Tayal people, which gives it special status in Tayal culture. In addition, because there is a higher cultural homogeneity of the Tayal tribes in this basin, the collaborative defense rights of the Tayal in this basin are far stronger than those of the other watershed.

Ownership and defense rights extend to ancestral lands and resources and are part of Tayal culture. The nature of Tayal culture is where disputes of ownership and rights conflict with current ownership and land-use practices. In Tayal culture, land defense rights include the mountains, forests, land, and water systems where the Tayal ancestors migrated to and settled well before any other people. Their rights are included in their memory (culture) and involve disputes over state claims and ethnic rights. According to the Tayal people, these lands and watersheds, wetlands have been passed down to them by their ancestors for thousands of years as their right of cultural inheritance, knowledge, and livelihood. Disputes between tribes generally have nothing to do with the state and because the words "country or state" and are not part of the Tayal vocabulary or understood in the Gaga scope of Tayal rights. How to deal with issues between tribes and the state/ government is not a normal part of Tayal culture and business and this is where problems arise. Tribal equality, fairness, and harmony is mainly based on sharing of water resources and fish in the water within the tribe's boundaries, not geopolitical boundaries/lines and modern law.

The tribal elders humbly mentioned that poison ivy had been used for fishing in the past to meet basic requirements for life, but when used, the tribes acted collectively to use the resources. Poison ivy is nature's version of rotenone, which is a chemical that is added to water to kill fish, but it also kills every living organism in the water body to which it is applied. When poison ivy was used in the past the fish that that were killed were divided equally between tribes according to the number of people regardless of age or sex. The collective belief was based on serving the needs of the community rather than the individual. If someone were to take extra fish privately, they would then be punished by Utux because of nyux mita Utux. The elders said this technique is not used today, but their admission that it was used in the past indicates a deep understanding of ecosystem biology, adaptation, and sustainability practices, because poison ivy too kills all of the other living organisms in the water too. Elimination of a technique that was known to work well, especially when food was limited and develop another that met the needs of the tribe in an 
environmentally friendly and sustainable manner further demonstrated their knowledge and relationship with the environment.

The elders we interviewed believed its impossible for all of the Tayal people to understand Utux and whether the current concept is consistent with today's fast-paced changing world. This is not unexpected given that there is variability in faith. Utux is difficult to understand if one is not immersed in the culture daily. The tribal elder's role is perhaps more complicated today than it was in the past because they need to provide clarity, unity, and direction around rapidly changing conditions for concepts and practices that no may no longer make sense to younger tribal members that are trying to adapt to today's needs, make a living, and raise a family. Moreover, an elder's norms and values may be reflections and interpretations of Utux and Gaga that could be hundreds of years out of date compared to today's norms and values. The concept of protecting your wetland resources because the lives of your people and culture that your ancestors depended on is really no longer valid or recognized. The Tayal people are also part of modern society and they too are not immune to the environmental and social issues we all face. Starvation is no longer a concern. There are food banks and grocery stores that can be used. While Utux and Gaga are primary components of Tayal culture, they too need to remain current and relevant with today's rapidly changing norms and values. The attention given to the planet's natural resources such as wetlands and water in the media may in fact be helping the elders remind the people of their tribe and their environmental responsibilities. Under Utux the Tayal people are the environment and they periodically need to be reminded of this though oral histories/ stories, guidance from the elders, and ritual practices.

\section{Language}

If we adopt the basic assumption that if there is language, then there are facts and meaning. Languages are cultural manifestations with meaning. The Tayal have no alphabet and their data are verbal translations and/or interpretation of the norms, values, and concepts of their culture at the time the story was developed. Contextually this means their culture needs to evolve in concert with societal norms and values. Consequently, without communication between the elders and tribal members the ideas, thoughts, and the intent of meanings in a modern world can become distorted. As indicated previously, what may have been important in the past may no longer be relevant. The elder's role in this process is similar to that performed by science historians. Kuhn (2012) described the role of the science historian is twofold. First, they are responsible for keeping track of the people associated with scientific progress in their culture. Second, they need to describe or explain the myths, errors, and superstitions that inhibited the more rapid accumulation of elements that comprise normal science.

The Tayal's concept of land is based on the following description provided by an elder is a good example of the relationship between culture and language. The land is borrowed from the sky. We must cherish and value it. The value of land does not lie in how much profit it can create, but in its ability to extend our lives. We were dead and kept intact and continued to be used by others. The boundaries of land, rivers and streams are different from the administrative regions. Tribes dominate and the boundary between tribes are the ravines and mountain ridges. Private land is the same as specified by the government. The two banks of the stream are bounded by the middle line of the stream, and the river section is bounded by the tribal Groups boundary. For example, Gogan and Mqwang stream are bounded by the salutz. (砂崙 子) tribe in Sanqwang Li (三光里), Fuxing District (Respondent, 160,317). The Tayal believe we live in a land, which is the body of Utux, so it must be cherished and protected. They also indicated that if they have forest, land, and water, they can survive because they have Gaga and can manage their environment. The ethics of the mother's land represents the universal view of nature in the Tayal people's world.

Dunbar (1995) suggests what we see and experience is determined by our language and culture, and translations from one culture to the other are essential for unity. Most environmental topics are strongly influenced by science and interpretations that are based on western approaches that the public is provided through various media outlets. That is, we can pick any magazine standing in line at the grocery store and environmental issues, if they are even mentioned are founded on a western and not indigenous science paradigms, Furthermore, scientists themselves live and work in a world where they are culturally conditioned through a process built on consensus that is modified by the intellectual climate, politics, culture, and environmental problems at that time (Goldstein and Goldstein 1985). That is, the science and facts we are presented with by the scientific community is a reflection of the cultural norms and values of the public at that time and they too, are subject to change spatially and temporally. We are rarely given the opportunity to experience or hear about indigenous cultures and details of their culture, spirituality, and environmental relationships. As such, differences in opinion and philosophy are accentuated between stakeholder groups because the elements that each group considers important at any point in time are intellectually, geographically, and culturally driven, and often give rise to or fuel controversies.

In science, controversies are well documented and studied by historians of science (Goldstein and Goldstein 1985; Kuhn 2012). Holton (1979) indicated scientists rarely look at societal predicaments because of the lack of relevant scientific knowledge and their data are far removed from the reality of 
local populations. Although indigenous cultures were not, and are still not immune to the issues that have impacted the environment globally, hundreds to thousands of years ago they lacked the technology and some of the knowledge that we have today. Yet, the indigenous people understood environmental change was inevitable, dealt with change(s) through adaptation, and survived. Therefore, it is paramount that all stakeholders understand the concepts and lexicon of the other stakeholders if collaboration is the ultimate goal. The goals need to be clearly defined and language, communication, and meanings need to be consistent, understood, and unified. Like any other language in the world, variations in meaning (local colloquialisms) and context exist at every geographic location (e.g., see New England and Texas) and we should expect to see similar issues within and between the tribal groups today and back in time.

Languages can have different meanings for the same concept and can be ambiguous in how they are defined or interpreted. We've tried to recognize/identify the nuanced meanings of the language expressed by the Tayal elders to demonstrate the contextual variability within which the ideas and concepts were explained. Chen et al. (2018) studied the management of water and wetlands in the Tayal system and non-human biotic and abiotic elements of the Tayal people. Recognizing the role of water and actively participating in the governance of public property, the management of public property in the Tayal context involves the more-than human world and the adaptive governance relationship between nonhuman and human agencies. Both participate in the Tayal's public management rights and establish a culturally appropriate, fair, and flexible public property governance framework in Taiwan's cultural landscape. The Tayal people manage water resources not only to manage the resource itself, but also, to manage the relationship between non-humans and humans, non-humans and environmental resources, and to share responsibility in the human and other than human world. Taiwan's non-indigenous people must recognize that the Tayal's guardianship of the country's natural resources is a sound basis for proposing a more culturally adaptable, fair, and flexible common property governance framework in a controversial and changing cultural environment. The controversial cultural landscape of Taiwan's Tayal territory reflects a persistent ontological diversity (Chen et al. 2018; Howitt and Suchet-Pearson 2003, 2006), and all claims to the land need to be recognized by the government and citizens of Taiwan.

Our observations indicate that the Tayal people are well aware of the current global issues and recognize their language is the only mechanism available to disseminate their knowledge and understanding of the issues to the people inside and outside of their tribes. Language is an important element of Utux and the Tayal people and we presume those of Taiwan's other indigenous cultures are working hard to preserve their languages. They have thousands of years of experience understanding and refining their learned environmental knowledge and management concepts, thoughts, and practices that they felt worth learning, preserving, and passing to future generations through stories. Unfortunately, thousands of years of observations are often minimalized or ignored because the gathering systems of western and indigenous knowledge systems are different and not necessarily aligned with indigenous systems. To our knowledge, western and indigenous scientific data are not frequently shared or shared as much as they could or should be. As such, processes to align the data from both groups and proper credit or acknowledgement of who generated the data are needed so that they complement one another. Collectively, these data may resolve some of the emerging environmental issues we currently and expect to face in the future. Collaboration and development of a shared data management system that meets the needs of the people and cultures, and protect Taiwan's incredibly diverse ecosystems that could be impacted in light of the global change scenarios should to be a priority at the highest levels of leadership.

\section{Environmental Justice}

Environmental Justice includes a wide range of examples that incorporates the use and management of geographically diverse environments, cultural relationships between humans and non-humans, and an ecological understanding and role of the spirit to influence people's actions to jointly build a sustainable environment. The Tayal people don't necessarily need western ecological theory because they are already a part of the ecosystem and experience it every day because they regard themselves as a part of nature. The intention expressed in Tayal language is a question of whether their cosmology and practice are unified, especially from Utux's point of view and how well Gaga is practiced by the people. The degree to which Gaga is embraced by the people of the tribe is the basis for understanding Utux and the role that humans and nonhumans play in developing sustainable ecosystems. Humans and spirits are not separate, and humans and nature are interconnected (Schlosberg and Carruthers 2010). The caring side of the Tayal language provides their view of EJ, the environment, and understanding of how best to maintain and protect these resources. This involves recognizing Utux's relationship with the environment. Chen et al. (2018) argue that it is impossible for the Tayal people to live without an Utux point of view because their culture is built on the environmental and ecological relationship between the land and the people and the Tayal understand and know natural resources are necessary for life. The problem lies in how these resources, some of which may be limited, can be developed or sustainably maintained without putting the tribes at risk. Most indigenous cultures have their own view of nature, guard their natural 
resources, and in general care about the EJ of the entire planet (Robyn 2002). Therefore, learning, interpreting, and the politics and issues that the Tayal people face today and navigating the current political landscape is a new skill that needs to be learned and passed to future generations to ensure the relationship(s) between the Tayal people and the environment are maintained or strengthened.

The EJ movement is relatively young and provides the Tayal people with a support system when environmental issues arise. The Tayal people's international connectivity and environmental stewardship is far-reaching because the environment is not defined by geopolitical boundaries and stewardship approaches should be unified and not geopolitically different. Past historic data show disputes and conflicts between and within tribes often occurred mainly because of hunting ground or land issues. The Mrqwang and Mknazi had little contact for a substantial period of time, but because they share a common river/ecosystem that substantially influenced the character of the natural ecology and their culture, the relationship between their tribes was re-established and new, stronger relationships were forged under a common belief. This example illustrates that the two groups sharing common ground were reunited on the cultural foundation of Gaga and rituals. Gaga's implied quantity and energy extends to the overall quantity and energy of the connection between humans, spirits, and nature. The use of Sbalay to solve problems suggests that this is an approach is much more efficient than approaches currently used. From an EJ perspective, the Tayal have the opportunity to exert/implement their rights, initiative, and motivation, giving full play to the caring capacity of humans, spirits, and ecosystems.

\section{Conclusions}

Berkes (1999) concluded in the analysis of global TEK systems, that TEK is comprised of local observational knowledge of species and their environment, how people use their environmental resources, and how the people fit into or relate to their ecosystems. The need to categorize indigenous knowledge and management systems are products of western science. While each indigenous culture on the planet has its own body of knowledge, resource management system, and scientific value that it could bring to the scientific community, the development of classification systems and ancillary definitions for cultural practices already known to the people is realistically, of little to no use to them. Nevertheless, a detailed analysis building on Berkes et al. (1999) assessment of TEK and TEM systems might provide a portal to assist western and indigenous scientists the opportunity to identify and develop solutions to global change issues that impact us all. This however, is a massive effort and well outside of the scope of this paper. Both parties will need to work together to develop and agree on the appropriate scope of the work to compare and contrast the benefits and limitations of indigenous and western scientific knowledge and management systems in any useful manner and how both systems can be flanged in a useful manner.

In a broader context, it is not only necessary to understand Tayal language, but the how, why, and context in which the words are used. While the members of each tribe speak the same language, the expressions and linguistic nuances contribute to the tribe's culture and individuality. Therefore, explaining the ideas/concepts well and listening for understanding are crucial to minimize misunderstandings and disagreements, especially when spirituality is included as part of the discussion. This is especially important with communications between Tayal and non-Tayal people. We need to understand, support, and respect the cultural context of the Tayal people and practice sustainability in our environment in ways that the Tayal and other indigenous cultures already practice. Moreover, to the best of our ability we need to understand the relationship between Tayal knowledge systems and spirituality and involve/incorporate the ontology and epistemology of Tayal knowledge and practices into our current policies and ecological management systems. This highlights the importance of integrating EJ into modern ecological management systems.

Utux is the Tayal people's belief system and Gaga embodies Utux's beliefs. The Tayal people's method of ethnic identity and ancestral relationship is called "lmuhuw" (tracking, quoting, reminiscing), and has always been a way of telling stories by the Tayal elders to track ethnic relations, history of movement, relationships, bringing tribal groups together (Xiao and Wang 2016), and avoiding incest and disunity within tribal groups. Utux and Gaga are the collective cultural experiences of the Tayal people, which includes the plants, mountains, and rocks and relationships between the environmental and ecological consciousness of the people. Of course, it does not include the young Tayal people living in the city because many have lost the understanding and use of their culture. The ability to communicate in their own language/dialect is the biggest problem that the Tayal elders worry about.

What can western science learn from the indigenous people of the world, including the Tayal, concept of the environmental protection and sustainability? First, the Tayal people's language and culture is based on the principles of Utux and Gaga and an oral record of the people's history and relationship with the ecosystems that sustain them. Cultural and language variations, nuances, environmental interpretations, and management techniques are specific to tribal groups based on differences in geographic location, environmental settings, and the wetland resources available to the people within their respective habitats. The use of EJ concepts as they relate to water and their resources to explain the interconnected relationship 


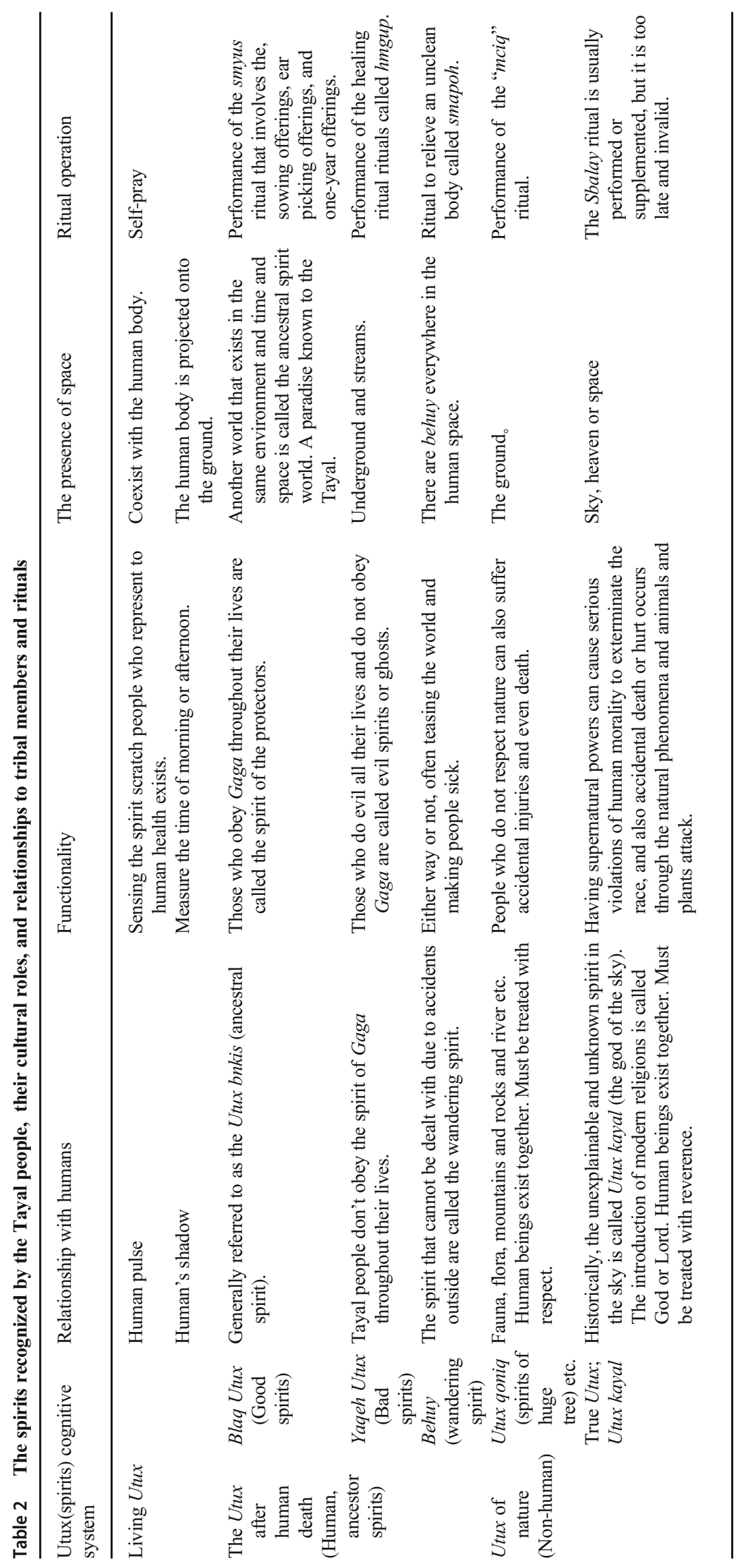


between Utux and Gaga is understood by the Tayal people and differs from that seen or understood by western scientists. The Tayal people believe in Utux, which affects their motivation and behavior. Their belief system plays a pivotal role in all aspects of tribal life and the management of ecological resources. To the non-Tayal people, a good understanding Utux is complex because Utux may be functionally different from tribe to tribe. Nevertheless, the belief in ancestral spirits is a pillar that unites the Tayal and other indigenous tribes. Furthermore, the people rely on Utux's philosophy in the collection and utilization of natural resources, ritual practices, resolving tribal boundaries, fighting for EJ, and lifestyle choices. The meaning of Gaga is even more complicated because it supports the spiritual relationship between Utux and Gaga and that you are in me, and me are in you, as well as the cultural belief that the Tayal people are an integral part of nature. Utux is non-human and Gaga is the ultimate result of the Tayal people's good deeds. We can specifically integrate the laws of nature and human behavior as a practice to understand the relationship between the Utux and Gaga of the Tayal people, but our results challenge the view or opinion that Utux and Gaga are static. Based on our results we can conclude that Utux and Gaga, and therefore Tayal culture changes spatially and temporally.

This review shows that the Tayal people's cultural collective is based on the tribal group's Gaga. The tribal group cultures differ from one another because the natural resources that contribute to their culture differ within and between from habitats. Moreover, the tribal boundaries are based on natural features of the environment and differ substantially from the government's administrative districts. While the government's approach simplifies the geographic division of a country or region, the unintended result is that the people of different tribes and/or tribal groups are treated as one homogenous group rather than a collective of tribal groups, or each tribe with its own culture and language. This not only creates cultural and administrative problems between the Tayal and other.

For indigenous tribes and local governments, it fosters controversy between the tribes that artificially have been grouped together. In addition to the elimination of the tribal rights of the mountains, wetlands, forests, and the natural resources of the Tayal and other indigenous tribes that have been part of their culture for thousands of years are now considered to belong to the country. This unfortunately contributes to the cultural decay of the Tayal and Taiwan's indigenous people. Moreover, the strength and economic model of mainstream society and agricultural production methods have changed Tayal society, especially the loss of their language, which has also greatly affected the ability of future generations to maintain harmony with the environment. It is worth mentioning that the tribal struggle to protect their land, Gaga, language, and culture left by their ancestors is an important EJ issue. At the same time, they believe that integrating tribal unity is the most difficult, because tribes have different cultural norms and beliefs. While homogenization of indigenous cultures may have been an unintended consequence to separate the tribes the return of ancestral beliefs and cultural norms, which allowed the Mrqwang and Mknazi tribes to reconcile their differences was a result. Sbalay remains an effective mechanism to resolve disputes and perhaps should be considered to resolve some of the social, economic, political, and environmental issues that modern society faces today.

Clearly our ancestors managed the resources in their environments well enough to survive as far back as 3.5 million years ago. Life and survival were priorities and the human population and the incredible cultural diversity we recognize today is a testament to our ancestors and their ability to adapt to changing environmental conditions. Despite the unsophisticated nature of their wetland (and natural) resource and environmental management strategies, they were born out of necessity. Through time, the people ensured that the accumulated knowledge, language, and culture were passed to future generations through cultural rituals and oral histories. Perhaps it is time to revisit what our ancestors learned and what we've forgotten.

Our natural resources now need to be managed better to attain maximum functional and sustainable benefits. This is important as we try to execute solutions to our current environmental problem, but implementation of governance tools must be consistent and equitable. However, at the international level environmental governance has a long history of biases and imbalances in regional, cultural, ethnic, gender, and linguistic perspectives (Davies et al., 2020). The western science and Tayal communities possess immense spatial and temporal data sets that when combined, could provide new options for future resource management. The knowledge and management systems of both groups are complex and require considerable expertise to interpret and/or understand the data. Despite the cultural and methodological similarities and differences between both groups, opportunities abound to build starting points to identify and resolve environmental management issues that impact both communities.

We may be on the cusp where the interrelationships between sound science or what Kuhn, (2012) called normal science, TEK, TEM, and global change are recognized and solutions to resolve environmental issues that benefit the environment and social issues that benefit the stakeholders are developed. While we believe it may be presumptive to consider the use of TEK and TEM approaches together with western scientific approaches to resolve environmental issues as a paradigm shift, Kuhn (2012) uses these three to define a paradigm shift. The world's view on global issues has changed, puzzles in the current field of knowledge remain, and TEK and TEM ideas are relatively new to scientists. 
Taiwanese immigrants appeared between 11,000 and 26,000 years ago and they brought their own versions of TEK and TEM knowledge with them. The Tayal and Taiwanese indigenous concepts of environmental preservation and sustainability extend much further back in time than that of modern scientific methodology which can be extended to the 1600 's. Nonetheless, we will leave it to the reader to make their own decisions.

Specific findings of this work include:

1) The setting of various taboos to prohibit certain areas or certain actions can benefit the environment by avoiding excessive environmental use and the depletion of its natural resources.

2) Tayal ritual practices are a reflection of their cultural and philosophical respect and reverence for nature.

3) Tribal cultures include belief systems, knowledge, social conventions, regulations, and language and can contribute to the excessive disturbance and depletion of our natural resources.
Appendix 1 - Questions posed to the elders during the interview process

1. What is the meaning and concept of Gaga?

2. What is the meaning and concept of Utux?

3. What is the Tayal's concept and meaning of environmental?

4. How do you explain Heaven, Earth, and people?

5. How to choose a site for the Tayal people's habitat?

6. How do the Tayal people manage water and utilities?

7. How do the Tayal people manage the tribes and claims?

8. What does Sbalay means and how does it work?

9. What is the process and results of the Gaotai (高臺) Dam Project? 


\title{
Appendix 2 - Summary of responses to the questions posed to the tribal elders in Appendix 1 and an analysis of the responses
}

\author{
Respondents Information Summary \\ Analysis \\ Code
}

090706(90) Utux has true gods, good spirits, bad spirits, evil spirits, wandering souls (behuy) and ghosts. The true god is called Utux kayal in Tayal refers to the gods of the Han people. It is the good spirit to keep Gaga throughout the life. After death, go to the ancestral spirit world (intuxan). Both good and bad are called ghosts. People who do a lot of evil become evil spirits after death and continue to harm the human world. God is called a woven spirit, and a woven is called a good destiny, and vice versa. Utux is found in mountains and rivers, rock plants and animals.

Tribal boundaries are based on the ridgeline of a ravine or mountain. Streams are based on tribal groups. For example, the Gogan and Mrqwang groups are based on the salunts tribe. Over the boundary line is the Sbalay reconciliation with pigs as affords. In the early days, the tribal elders took the lead. Now there are the official chiefs, representatives, district heads or township chiefs who preside over justice, and the affords remain unchanged.

090612(79) God. The spirits after death are the spirits of ancestor spirits. They will go to the ancestral spirit world by guarding Gaga throughout their lives. The man dead in the wild are not brought to home and just buried in there, these are called behuy. Those who do not obey Gaga all their lives are called evil spirits or ghosts in underground. No other trees, lakes and rocks Utux. But you can create freely, and I have no objection. But the ancestor spirit is not the object of our worship, but the spirit of heaven. Because our tribes don't worship idols, you can go and see if each tribe has a portrait.

090612(85) Utux kayal is the spirit in the sky, with very powerful power, Utux Bnkis is a good spirit, and will protect our lives. Everything else is bad. Animals, trees, mountains, rivers, and rocks all have Utux. Like siliq(a Bird), It will tell us about the future, especially when we go hunting or go to the seeking marriage to rely on it to inform, we Utux(value) it very much.

150,720(66) The first one, Gaga starts from a kind of origin (tringan) essence meaning, then we talk a lot about things, why is life like this now? What do the Tayal people say? Why does the sun rise from the east, and why does it fall to the west? So why is this? "Gaga nia"! Gaga nia! This meaning "it turns out to be like this" is a natural phenomenon. Therefore, the natural phenomenon, the meaning of Gaga, is its main origin. So our ancestors said that if our Tayal people did not have Gaga, they could live casually, and would extinct their race and families. Without Gaga, we just love it! We have this Gaga, so we can't live casually. So it means that before we humans appeared, Gaga already existed. The elders said, "Gaga nia!" This is a natural thing! This sentence is very profound. As soon as this ancestor says Gaga, we must obey it. Of course, the other meanings of Gaga are based on the rules of our ancestors.

160,314(75) My wife's transition from the terminal stage of cancer to health and even childbirth is completely inspired and perceived by Utux's belief in finding medicines for my wife, and it even allowed me to
Utux and Gaga are the collective cognitive culture of the Tayal tribe. Other related plants, mountains and rocks are basically the relationship between the environment and ecological consciousness built by the tribal hunter-gatherers. Of course, it does not include the young Tayal people living in the city. Because they have almost lost understanding and use the abilities of culture and mother talks, and this is also the big thing that the tribe elders are worried about. This article believes that the Tayal cultural collective still divides the tribal boundaries based on the inherited Gaga norms. This is different from the modern administrative district based on the village. They always group several different tribes into one administrative area for convenience, which is beyond the identification boundary of Tayal people. In addition to private rights, other mountains, forests and rivers belong to the states, which limits the life and cultural activities of the Tayal people. Moreover, the strength and economic model of the mainstream society, as well as the methods of agricultural production, have changed the society of the Indigenes. Especially the rapid loss of language, which has also greatly affected the ability of future generations to maintain harmony with the environment. It is worth mentioning that Tribal people struggle to protect the land and Gaga (Gaga here can be collectively referred to as cultural meaning, including language) left by their ancestors and their descendants to express their extensive ecological justice. At the same time, they believe that integrating tribal unity is the most difficult, because tribes have different modern religions, and each tribe has different beliefs. This is the easiest time for the government to differentiate tribal people. However, through their anti lobby group conducted in night persuasion, they returned to the identity of their ancestral beliefs, staged the reconciliation between the Mrqwang Group and the Mknazi Group, abandoned the obstacles of disunity in the past, and renewed their mutual belief in the ancestral spirits. Because the downstream of Mrqwang Group suffers the crisis, the upstream of the Mkanzi Group also same suffer forming their common recognition. Since the protests, activities until now, government planners have not entered the basin, and protests have taken place. So far, the appeal of ecological justice protestation is effective. They are based on the beliefs of Utux and Gaga, whether it is tribal autonomy or the use and collection of natural resources, there are rich ecological practices. The tribal reconciliation mechanism is still an effective mechanism for the Tayal tribal societies to effectively resolve no matter how controversies between the tribe and the tribe, the tribes and the state. The tribes have a firm will to defend their forests, lands and Waters, and they will continue to pay attention to the follow-up actions of the government. 
change my conventional agriculture and recreate ecological farming. Agricultural cultivation uses ancient methods to use plants and insects as natural farming fertilizers. Now family members are completely free from pesticide damage, and fruits and vegetables are sold well.

160,315(77) If we have forests, land, and water, we can survive. When we heard that the government was going to set up a large dam in the Mrqwang Valley, we gathered young people who were studying outside to return to the tribe to discuss how to solve it. The tribe crowd was so angry that they wanted to block the road and even threatened to kill one by one. The current government decree does not allow us to do this. We have inherited this issue from our ancestors in Gaga, so we can protect our watershed. The elderly still think that we should discuss it rationally. If the dam is built, where are we going? How is our culture maintained? Discuss what to do with the ancestor's land. The river is the source of our life, and the land is our mothers and ancestors. In the past, we were forced to speak Mandarin, but now we are forced to leave. How can we continue our lives and develop our culture? And how to unite people from other tribes. This is where we must build a consensus to unite and reflect our aspirations to the government.

The tribal boundaries are very good. Gaga is bounded by the middle line of the river. The Mrqwang Group and the Mknazi Group are bounded by the flagship rock, which is also a planned site for large dams planned by the Taiwan Government.

160,315(68) Around 2012, we very much hope that young people will return to tribes for agriculture and develop our culture. I am very worried that we are old and dead. These young people may have sold their land. Our Gaga is very good. I use shooting when I go to the streams to shoot fish. We look down on those who use fishing nets and are laughed at. They are not mliquy balay (Tayal men). It takes a long time to cultivate fish shooting skills. Like me, I have learned more than 10 years before shooting fish. I am not afraid of rapids. We will do rituals when we enter the water. We will also share with the spirits of the streams when we cook rice by side of the stream. The fishing will stop when we are enough for our family. we will not overdo it. When there are no fishes after the typhoon passes, we will go downstream to catch small fish and put them back to our streams. This is what we often do.

160,316(80) The trees we need to grow shiitake mushrooms were all planted on my land when we were young. In exactly 30 years, I cut down and planted wood mushrooms. When we cut the tree, we will leave about one meter of roots and let the roots continue to grow. Tribal boundaries are the same as land boundaries and river boundaries. They are all bounded by the ridgeline of a ravine or mountain. Each does not cross each other, and the tribe lives on its own. In case of dispute, we will conduct sbalay.

160,317(77) The land is borrowed from the sky. We must cherish and value it. The value of land does not lie in how much profit it can create, but in its ability to extend our lives. We were dead and kept intact and continued to be used by others. The boundaries of land, rivers and streams are different from administrative regions. Tribes dominate. The boundary between tribes and tribes is dominated by ravines and mountain ridges. Private land is the same as specified by the government. The two banks of the stream are bounded by the middle line of the stream, and the river section is bounded by the tribal Groups boundary. For example, Gogan and Mrqwang stream are bounded by the salunts(仯耑子) tribe in Sanqwang Li(三光里), Fuxing District.

160,617(73) The sowing ceremony is to pray for the protection of Utux to have a good harvest. We use a multi-species and multi-family mixed planting method for one piece of land. We do not weed the surrounding area to allow more insects to choose and reduce crop damage. The slopes of the fields will be piled up with stones 
and arranged neatly. On the one hand, they are used to prevent soil and rock flow. On the other hand, they allow frogs to stay and feed snakes. This ecological farming method. At the same time, they will have a variety of crops, which can be eaten in a variety of crops, and the harvest will be distributed to disadvantaged families or households without land.

170,621(45) Many of our pastors and young people set up an anti-lobby group, every night to persuade different sects in the tribe to unite and fight together, do not agree to the government's multi-million temptation. Different sects have different opinions, and finally the ancestral beliefs are used as rituals to successfully integrate the unity of the tribe.

170,630(32) We women worked hard at night, not only to prevent the government from entering the tribe, but also to persuade the tribe people to unite outside. The tribe has Christian elders, Catholicism and true Jesus sects. How to integrate these can only be returned to the ancestral belief, because the ancestral spirit will protect us, and the ancestral belief is still acceptable at present.

170,705(63) We mobilized to every tribe almost every night to explain and publicize, especially the pastor in Tianpu who worked very hard to take us from house to house to convince tribesmen not to be deceived, and by the way, tell them about the ecology that will be produced after the Shimen Reservoir in Fuxing District is built. The destruction and the current living conditions of the displaced people are far away from our local culture.

170,705(72) The dam struggle is mainly led by our Mrqwang Group. I am very grateful to the university professors and students to help us. Almost all young people are mobilized, using computers to distribute propaganda and leaflets. The government used the night secretly to persecute people to lure people of different sects. We also specially set up a propaganda group and anti-lobby group to recruit young people studying abroad to return to the tribe to discuss how to resolve their complaints to the government. The lobby group promoted the ideas and practices of the tribe, and even decided to close the mountain so that early planners would no longer enter our territory. The anti-lobby group, especially the pastor from Tianpu, actively persuaded the tribesmen to unite to have hope. Because there are too many sects in the tribe, each has its own ideas, and finally we use the beliefs of our ancestor spirits to inform the ancestor spirits in the pre-determined place of the dam, and we are determined to protect our land. We have Gaga inherited from our ancestors, we can protect the river and fish to protect our first river. We use the natural poisonous fish method, and it is the tribe as a whole, and the fair is based on the number of people. There are as many people in the family as men, women and children. If someone steals more fish, that person will be punished by Utux and injured. Almost no one does this. It's the same with dividing pigs, this is our good Gaga. Where are we going to build the dam? The government says we will be moved to the Hengshan Han people's place. Those lands are not known to us. What about our culture? What about the graves of our ancestors? We will live in the city like the Kara tribe in Fuxing District and become rootless people. We also went to the Brazilian representative office in Taipei to support the native Amazons in protesting their government's construction of large reservoirs.

170,630(70) Our Gaga is very good, that is our life culture, my father did not talk about the specific content. But the sharing of pork is a good example, regardless of whether young or old men and women share equally, this is our Gaga. Tribal boundaries are based on the ridgeline of a ravine or mountain, and streams are based on ethnic groups. Adhere to the preoccupied of Gaga, whether it is 
a tribal hunting area or the use of water, you must first obtain the consent of preoccupier and provide pig sharing.

170,703(68) "kayal", in addition to the meaning of "heaven" (the sky or Lord), it also has the meaning of "speaking", which means "talking". We say "kayal ta ke" (talking or chatting), which means we use " "Heaven" (implied spiritual power) is the prerequisite for conversation. The standard of true and false conversation is under the witness of heaven. You cannot deceive or lie, because the spirit of heaven is watching and people should tell the truth. God is Dominate everything, everything is changed by heaven, and we cannot change it.

"Hiyal" (land), "hi" means "body" or the meaning of his (it, her and its), his celestial body or his things. In the Tayal language, "hiyal" is not only the earth, but also the heavenly body.

"Hiyal" plus the prefix "l" means lhiyal. This land means that many resources are gathered. "l" comes from the word source of "lhuiy", which means "seed", which means that the land has grown many resources. It means that seeds can continue to grow naturally. Humans, animals and plants are trained by celestial bodies, and they must treat their celestial bodies with gratitude and the duty of protection. They cannot destroy them or desecrate their bodies, otherwise they will be harmed.

"Ta" in "tayal" means "we", which means that we must follow the meaning of "kayal"; that is, including the meaning of "tayal", we cannot change the meaning of "heaven", meaning that "we" (tayal) stands On His celestial body, and mentioned before we can survive, everything must "listen to it." We must know the meaning of its roots in order to understand the meaning and direction of the so-called heaven, earth and man. All the "heaven, earth and people" in a concept have a triple relationship. "Heaven" is the power that governs all people or all things. These are all derived from the meaning of heaven.

171,115(68) A Han man brought 15 million yuan (NT\$) in cash to the old man (Yike•Sulong) who wanted to buy local land, but the old man told him: Your money is very good, but your money cannot recover and protect ours Culture. However, the Han people did not give up and returned to the old man with more than 50 million yuan in cash. The old man told him: "Your money is good, but your money cannot cultivate and nurture our millet and sweet potatoes, nor can it continue. The lives of our children and grandchildren. 
Code Availability N/A.

Authors' Contributions KSS and WTF performed the field work/ interviews and data analyses and KSS, WTF, and BAL contributed equally in the preparation and writing of this manuscript.

Funding Funding for this research was provided to KSS by the Ministry of Science and Technology grant number MOST 105-2511-S-003-021MY3 and subsidized by the National Taiwan Normal University (NTNU), Taiwan, ROC. Also referenced in the paper.

Data Availability Data are available upon request to KSS.

\section{Declarations}

Ethics Approval KSS paid at least NT $\$ 1000$ to each interviewee for their data, permission to use their data in our paper, and consent to use their data in this paper.

Consent to Participate and Publish KSS paid at least NT\$1000 to each interviewee for their data, permission to use their data in our paper, and consent to use their data in this paper.

Conflicts of Interest/Competing Interests There are no conflicts or competing interests.

\section{Suggested Reviewers Done.}

Open Access This article is licensed under a Creative Commons Attribution 4.0 International License, which permits use, sharing, adaptation, distribution and reproduction in any medium or format, as long as you give appropriate credit to the original author(s) and the source, provide a link to the Creative Commons licence, and indicate if changes were made. The images or other third party material in this article are included in the article's Creative Commons licence, unless indicated otherwise in a credit line to the material. If material is not included in the article's Creative Commons licence and your intended use is not permitted by statutory regulation or exceeds the permitted use, you will need to obtain permission directly from the copyright holder. To view a copy of this licence, visit http://creativecommons.org/licenses/by/4.0/.

\section{References}

Berg KJ (2013) Ecological and ethnoecological classification of a forested landscape in the Tayal Mrqwang territories, Taiwan (ROC). University of Guelph, Dissertation

Berg KJ Lin YR, Icyeh L (2017) Ecological and ethnoecological classification of a forest landscape near Smangus Village in the Tayal Mrqwang Territories, Taiwan. In: Kuan, DW (ed) Ethnos, geography and development: An interdisciplinary approach to humanenvironmental relations. Shung Ye Museum of Formosan Aborigines, pp.163-191

Berkes F (1999) Sacred ecology: traditional ecological knowledge and resource management. Taylor \& Francis, New York

Berkes F (2012) Sacred ecology. Routledge, New York

Cajete G (1994) Look to the mountain: an ecology of indigenous education. Kivaki Press, Colorado

Chen YS, Suchet-Pearson S, Howitt R (2018) Reframing indigenous water rights in "modern" Taiwan: reflecting on Tayal experience of colonized common. International Journal of the Commons 12: 378-401. https://doi.org/10.18352/ijc.823

Cowardin LM (1979) Classification of wetlands and Deepwater habitats of the United States. WS/OBS-79/31: 1-131

Davies GT, Finlayson CM, Pritchard DE, Davidson NC, Gardner RC, Moomaw WR, Okuno E, Whitacre JC (2020) Towards a universal declaration of the rights of wetlands. Marine and Freshwater Research 72(5):593-600. https://doi.org/10.1071/MF20219

Dunbar R (1995) The trouble with science. Harvard University Press, Cambridge

Fang WT, Hu HW, Lee CS (2016) Atayal's identification of sustainability: traditional ecological knowledge and indigenous science of a hunting culture. Sustain Science 11:33-43. https://doi.org/10.1007/ s11625-015-0313-9

Goldstein M, Goldstein IF (1985) How we know: an exploration of the scientific process. DeCapo Press, New York

Hardin G (1968) The tragedy of the commons. Science 162:1243

Holton G (1979) The scientific imagination: case studies. Cambridge University Press, Cambridge

Howitt R, Suchet-Pearson S (2003) Ontological pluralism in contested cultural landscapes. In: Anderson K, Domosh M Pile S, Thrift N (eds) Handbook of cultural geography. Sage Publications, London, pp. 557-569. https:// https://doi.org/10.4135/9781848608252.n41

Howitt R, Suchet-Pearson S (2006) Rethinking the building blocks: ontological pluralism and the idea of "management". Geog Ann 88B: 323-335

https://english.cw.com.tw/article/article.action?id=2495. Accessed November 20, 2020

Kuhn TS (2012) The structure of scientific revolutions. University of Chicago Press, Chicago

Robyn L (2002) Indigenous knowledge and technology: creating environmental justice in the twenty-first century. The American Indian Quarterly 26:198-220

Schlosberg D, Carruthers D (2010) Indigenous struggles, environmental justice, and tribe capabilities. Global Environmental Politics 10:1235

Soga M, Gaston KJ (2016) Extinction of experience: the loss of humannature interactions. Frontiers in Ecology and the Environment 14: 94-101

Tajima A, Sun SC-S, Pan I-H, Ishida T, Saitou N, Horai S (2003) Mitochondrial DNA polymorphisms in nine aboriginal groups of Taiwan: implications for the population history of aboriginal Taiwanese. Human Genetics 113:24-33

Tang CP, Tang SY (2010) Institutional adaptation and tribe-based conservation of natural resources: the cases of the Tao and Tayal in Taiwan. Human Ecology 38:101-111

Tinker GE (1996) An American Indian theological response to ecojustice. Defending mother earth: native American perspectives on ecojustice. pp. 153-176. www.webpages.uidaho.edu/eng1501ej/ Tinker.pdf. Accessed 10/19/2020

Xiao SH, Wang MH (2016) Decolonizing cultural landscape representations: the making of 'chanting map' by Tayal people. Journal of Geophysical Research 65:107-142. https://doi.org/10.6234/JGR. 2016.65.05

Zebardast L, Akbarpour S, Jafari HR, Karimi MB (2020) Sustainable wetland management through bridging the communication gap between conservation projects and local communities. Environment, Development and Sustainability 23:11098-11119. https://doi.org/ 10.1007/s10668-020-01082-5

Publisher's Note Springer Nature remains neutral with regard to jurisdictional claims in published maps and institutional affiliations. 